\title{
The disadvantaged right ventricle in hypoplastic left heart syndrome: Additional insight
}

\author{
Charles D. Fraser, Jr, MD, FACS
}

Although significant progress has been made during the last 25 years in the surgical treatment of hypoplastic left heart syndrome (HLHS), the fate of the systemic right ventricle (RV) in this modified circulation remains unpredictable. ${ }^{1}$ Recent idealized prospective randomized series confirm the frustrating reality of treating patients with HLHS. For example, although 30-day mortality for stage I palliation has improved, overall intermediate-term survival remains disappointing. ${ }^{2,3}$ Much work has gone into the search for an explanation for this observation in an effort to protect or improve RV function, clearly a central causal factor in longterm morbidity and mortality. Areas of focus have included shunt type and source (systemic to pulmonary artery shunt vs RV to pulmonary artery conduit), early stage II palliation (bidirectional Glenn shunt), aggressive systemic afterload reduction, alleviation of residual arch obstruction, aggressive surgical treatment of tricuspid regurgitation, and others. ${ }^{4}$ The provocative study from Biglino and colleagues that appears in this month's Journal sheds additional light on this vexing problem of RV dysfunction in palliated HLHS. In fact, the study strongly supports a contention that every surgeon wants to believe: that technical modifications of our operations still can make a difference in patient outcomes.

Biglino and colleagues have examined the relationship between the method of stage I reconstruction in HLHS and ventriculoarterial coupling. Ventriculoarterial coupling describes the relationship whereby the ventricle, through the generation of hydraulic energy, transfers the mechanical energy to the arterial tree. ${ }^{5}$ This relationship is known to be deranged in systolic heart failure and is related to prognosis. $^{6,7}$ Although this mechanism has not largely been studied in RV systolic heart failure, it is intuitively apparent that the situation is only worse. For example, in the palliated RV, decreased coupling efficiency is likely correlated with poorer RV performance and ultimately prognosis. Although the study of Biglino and colleagues

\footnotetext{
From the Texas Childrens Hospital, Division of Congenital Heart Surgery and the Michael E. DeBakey Department of Surgery, Baylor College of Medicine, Houston, Tex.

Disclosures: Author has nothing to disclose with regard to commercial support.

Received for publication March 28, 2014; accepted for publication April 11, 2014; available ahead of print May 14, 2014.

Address for reprints: Charles D. Fraser, Jr, MD, FACS, Surgeon-in-Chief, Donovan Chair, Texas Children's Hospital and Susan V. Clayton Chair, Professor of Surgery and Pediatrics, Baylor College of Medicine, Texas Children's Hospital, 6621 Fannin St, MC-WT19345H, Houston, TX 77030 (E-mail: CDFraser@ texaschildrens.org).

J Thorac Cardiovasc Surg 2014;148:2419

$0022-5223 / \$ 36.00$

Copyright (c) 2014 by The American Association for Thoracic Surgery

http://dx.doi.org/10.1016/j.jtcvs.2014.04.021
}

did not demonstrate an effect of the shunt type (Blalock-Taussig shunt vs RV to pulmonary artery conduit) on ventriculoarterial coupling, the mode of arch reconstruction and arch size mismatch were observed to affect the coupling mechanism negatively. A logical interpretation of these data is that the increased afterload in a disproportionately large reconstructed aorta with the additional problem of abnormal mechanical energy transduction related to marginal elastic properties of the nonnative material used for aortic reconstruction (homograft or other bioprosthetic patch material) will have deleterious effects on RV function with time. For the congenital heart surgeon, this information should stimulate not only additional thought concerning the artistry of the arch reconstruction (ideal size and geometry of the reconstructed arch complex) but also the reconsideration of all autologous arch reconstruction methods. Our group and others have previously reported that all-autologous arch reconstruction is possible in most patients with HLHS, ${ }^{8}$ and many continue to use this technique exclusively (S. Sano, personal communication). Perhaps this methodology, or at least techniques that largely minimize the use of nonautologous materials in arch reconstruction, will offer further refinement of our ability to optimize ventriculoarterial coupling and thereby long-term RV function. Certainly, this study is highly suggestive that an ideal aortic arch repair in HLHS not only "looks pretty" but may be associated with a better long-term outcome.

\section{References}

1. Tweddell JS, Sleeper LA, Ohye RG, Williams IA, Mahony L, Pizarro C, et al. Intermediate-term mortality and cardiac transplantation in infants with single-ventricle lesions: risk factors and their interaction with shunt type. J Thorac Cardiovasc Surg. 2012;144:152-9.

2. Ghanayem NS, Allen KR, Tabbutt S, Atz AM, Clabby ML, Cooper DS, et al. Interstage mortality after the Norwood procedure: results of the multicenter Single Ventricle Reconstruction trial. J Thorac Cardiovasc Surg. 2012;144:896-906.

3. Ohye RG, Schonbeck JV, Eghtesady P, Laussen PC, Pizarro C, Shrader P, et al Cause, timing, and location of death in the Single Ventricle Reconstruction trial. J Thorac Cardiovasc Surg. 2012;144:907-14.

4. Elmi M, Hickey EJ, Williams WG, Van Arsdell G, Caldarone CA, McCrindle BW Long-term tricuspid valve function after Norwood operation. J Thorac Cardiovasc Surg. 2011;142:1341-7.e4.

5. Chantler PD, Lakatta EG, Najjar SS. Arterial-ventricular coupling: mechanistic insights into cardiovascular performance at rest and during exercise. J Appl Physiol (1985). 2008;105:1342-51. Erratum in: J Appl Physiol. 2009;106:1027.

6. Ky B, French B, May Khan A, Plappert T, Wang A, Chirinos JA, et al. Ventricular-arterial coupling, remodeling, and prognosis in chronic heart failure. J Am Coll Cardiol. 2013;62:1165-72.

7. Asanoi H, Sasayama S, Kameyama T. Ventriculoarterial coupling in normal and failing heart in humans. Circ Res. 1989;65:483-93. Erratum in: Circ Res. 1990;66:1170.

8. Fraser CD Jr, Mee RB. Modified Norwood procedure for hypoplastic left heart syndrome. Ann Thorac Surg. 1995;60(6 Suppl):S546-9. 